\title{
Right atrial perforation secondary to implantable cardioverter defibrillator insertion
}

\author{
Nam T Tran MD ${ }^{1}$, Adam Zivin MD ${ }^{2}$, Darius Mozafferian $\mathrm{MD}^{2}$, Riyad Karmy-Jones MD ${ }^{1}$ \\ Divisions of ${ }^{1}$ Thoracic Surgery and ${ }^{2}$ Cardiology, University of Washington Medical Center, \\ Seattle, Washington, USA
}

NT Tran, A Zivin, D Mozafferian, R Karmy-Jones. Right atrial perforation secondary to implantable cardioverter defibrillator insertion. Can Respir J 2001; 8(4):283-285.

Implantable cardioverter defibrillator (ICD) placements can be associated with serious complications. This paper reports a patient in whom percutaneous placement of an ICD resulted in a hemopneumothorax. This was due to an active fixation lead that perforated the right atrial wall and injured the adjacent lung parenchyma. The hemothorax was drained thoracoscopically, and the atrial injury was covered with fibrin glue.

Key Words: Hemothorax; Implantable cardioverter defibrillator; Video-assisted thoracic surgery

\section{Perforation de l'oreillette droite, secondaire à la pose d'un défibrillateur implantable}

RÉSUMÉ : La mise en place d'un défibrillateur implantable (DI) peut être associée à de graves complications. Voici le cas d'un patient chez qui la pose d'un DI par voie percutanée a entraîné un hémopneumothorax. Une électrode à fixation active a perforé la paroi de l'oreillette droite et a lésé le parenchyme pulmonaire adjacent. L'hémothorax a été drainé par thoracoscopie et la lésion dans l'oreillette droite a été recouverte de colle de fibrine.
$\mathrm{T}$ he patient was a 33-year-old man with hypertrophic cardiomyopathy who had undergone prophylactic implantable cardioverter defibrillator (ICD) placement by the Electrophysiology Service at the University of Washing- ton Medical Center, Seattle, Washington. He had an active fixation, atrial Medtronic lead (Model \#6943, Medtronic Inc, USA) placed using the left subclavian vein approach. Temporary stimulation at $10 \mathrm{~V}$ output did not show any extra car-

Correspondence: Dr Riyad Karmy-Jones, Division of Thoracic Surgery, University of Washington Medical Center, 


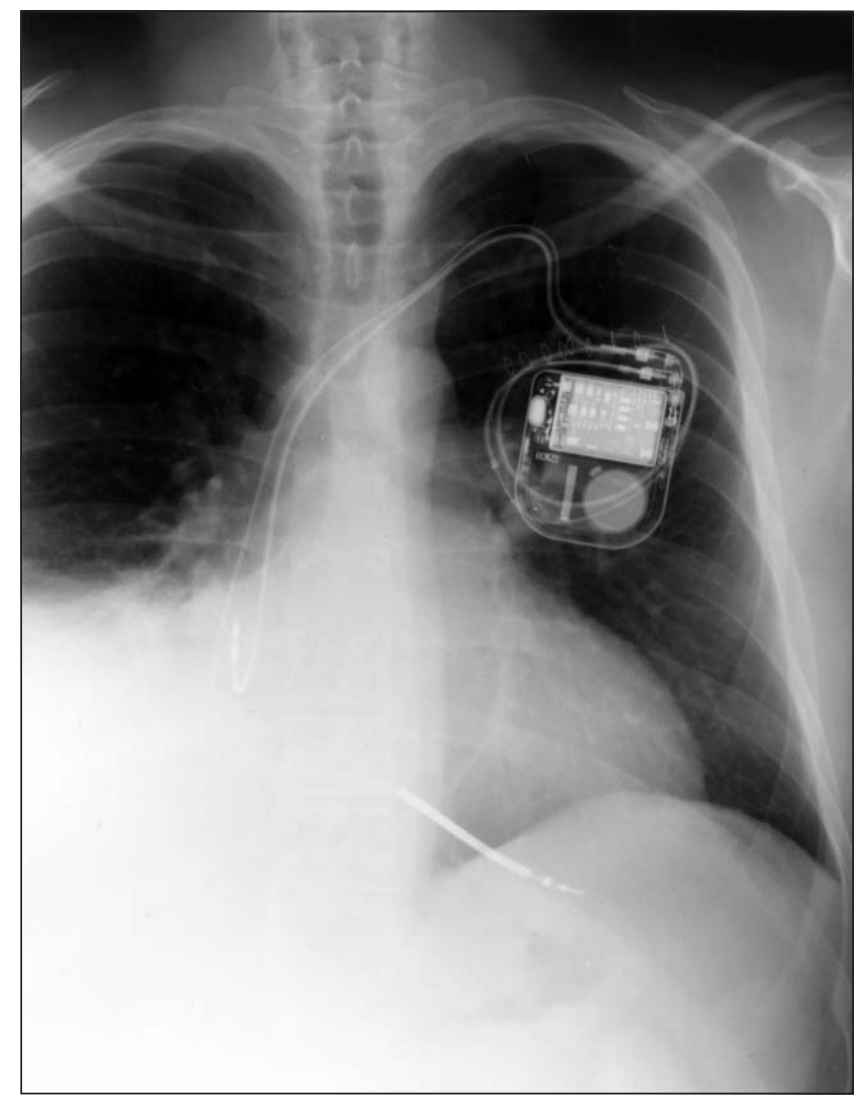

Figure 1) Posteroanterior chest radiograph showing right-sided effusion

diac stimulation. The patient's postprocedure chest x-ray (CXR) showed good placement of the lead, and no pneumothorax or effusion. He subsequently presented to the clinic on the fourth postprocedure day with left-sided pleuritic chest pain. A CXR performed at that time showed a small, right-sided pneumothorax and an effusion. The hematocrit was 37, while the preprocedure hematocrit had been 43. The patient was managed conservatively, and subsequent CXRs over the intervening three days showed resolution of his pneumothorax. However, the right-sided effusion continued to increase in size, with an associated decrease in the hematocrit (Figure 1). On the seventh postprocedure day, the hematocrit was 34 .

The patient was taken to the operating room for a planned right-sided thoracoscopy. This revealed a right-sided hemothorax with $1250 \mathrm{~mL}$ of old, unclotted blood. No vascular injury was noted, but on further inspection, there was a $1.0 \mathrm{~cm} 1.5 \mathrm{~cm}$ defect of the pericardium. Underneath this defect, the end of the active fixation atrial lead could be seen (Figure 2). There was no active bleeding. The site of perforation was closed with fibrin glue and Surgicel (Johnson and Johnson Medical Inc, USA). A chest tube was placed, and the patient was subsequently transferred to the ward for further observation. The patient did well, with minimal chest tube drainage. The tube was removed the next day, and the patient was discharged on the second postoperative day.

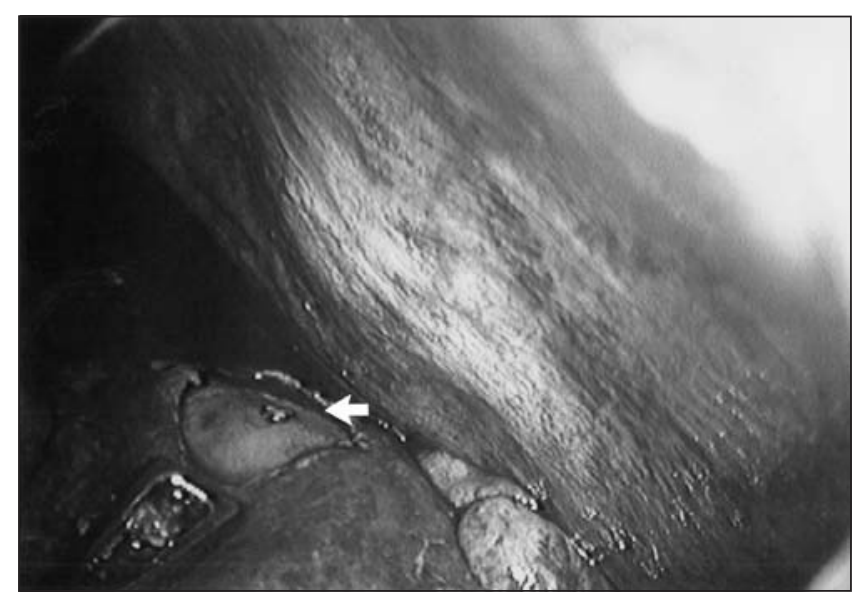

Figure 2) View of the pericardial defect with atrial lead (arrow), as seen during thoracoscopy. The pericardium was very inflamed

\section{DISCUSSION}

ICD placement by the percutaneous route is associated with a few periprocedural complications, including lead dislodgement in $4 \%$ of patients, lead adapter and/or insulation break in $4 \%$ of patients, and pneumothorax in $2 \%$ of patients (1). Others have reported isolated cases of acute, lead-related complications such as atrial perforation (2); these complications have resulted in pericardial effusion that was treated with pericardiocentesis (3). However, we could not find a report of lead perforation causing hemothorax.

By design, the active fixation screw penetrates the cardiac wall to prevent lead dislodgement. The lead used in this case did not use an electrically active fixation helix. Some models have electrical active fixation helixes that, when stimulated, may show abnormal extracardiac stimulation. Aside from fluoroscopy, there is no other method to detect whether the lead has gone into, or through, the cardiac wall. This is especially pertinent in the thin right atrial wall. In the present patient, it appears that the lead not only penetrated the right atrial wall, but also the pericardium and the adjacent lung parenchyma. Thus, the result was both a pneumothorax and a hemothorax.

When presenting with a hemothorax and/or pneumothorax after ICD insertion, the possibilities of both vascular and cardiac injury need to be kept in mind. In this case, injury to the superior vena cava due to the dilator or guidewire was a possibility. However, dilator and guidewire injuries usually occur in the immediate perioperative period. Furthermore, it was interesting to note that the hemothorax and pneumothorax were on the side opposite to the percutaneous insertion. In our case, the patient appeared to have sustained a cardiac injury from which he slowly bled into the right chest for several days.

\section{CONCLUSIONS}

Active fixation leads used in ICD placement can be associated with right atrial, pericardial and lung parenchymal injuries leading to hemopneumothoraxes (1-5). Usually, these will present in the acute setting, but delayed presentation can 
also occur. Thus, we would recommend careful follow-up of patients, and aggressive investigation when patients report symptoms of complications. When presented with hemothorax after ICD placement, one should keep in mind the possibility of great vessel and cardiac injury. Thoracoscopy is a viable diagnostic and potentially therapeutic tool in this setting.

\section{REFERENCES}

1. Grimm W, Flores BF, Marchlinski FE. Complications of implantable cardioverter defibrillator therapy: Follow-up of 241 patients. Pacing Clin Electrophysiol 1993;16:218-22.
2. Van Nooten GV, Verbeet T, Deuvaert FE. Atrial perforation by a screw-in electrode via a left superior vena cava. Am Heart J 1990;119:1439-40.

3. Glikson M, Von Feldt LK, Suman VJ, Hayes D. Clinical surveillance of an active fixation, bipolar, polyurethane insulated pacing lead, Part I: The atrial lead. Pacing Clin Electrophysiol 1994;17:1399-404.

4. van Rugge FP, Savalle LH, Schalij MJ. Subcutaneous single-incision implantation of cardioverter-defibrillators under local anesthesia by electrophysiologists in the electrophysiology laboratory. Am J Cardiol 1998;81:302-5.

5. Ho WJ, Kuo CT, Lin KH. Right pneumothorax resulting from an endocardial screw-in atrial lead. Chest 1999;116:1133-4.

\section{Supported by an unrestricted educational grant from}




\section{ERRATUM}

In the paper "Right atrial perforation secondary to implantable cardioverter defibrillator insertion" (Can Respir J $2001 ; 8[4]: 283-5)$, the name of the third author, D Mozaffarian, was mispelled. Our apologies are extended to Dr Mozaffarian. 


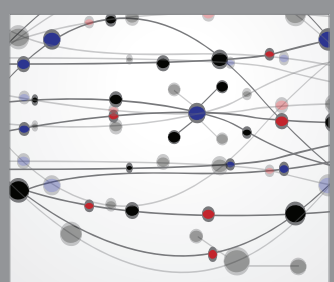

The Scientific World Journal
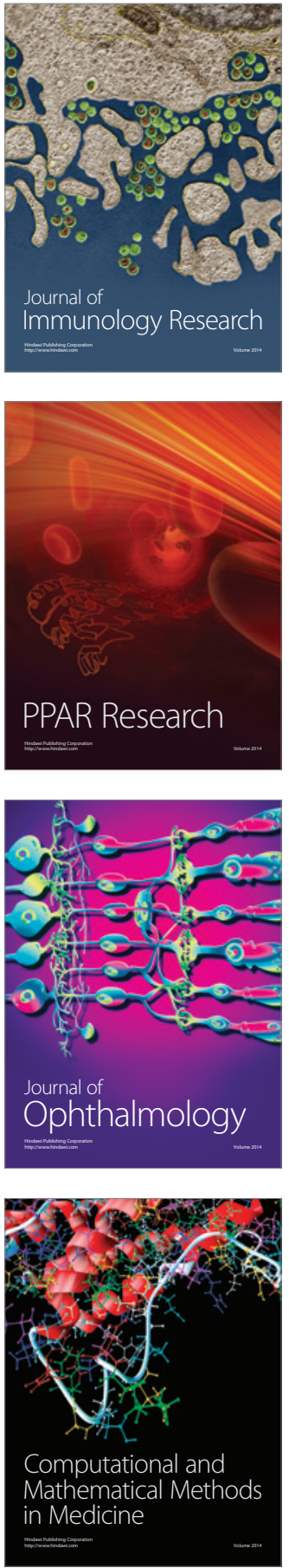

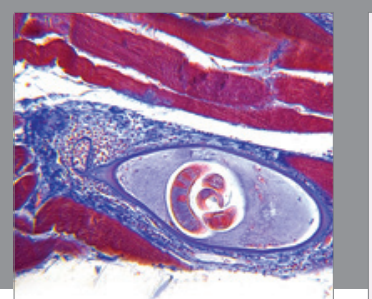

Gastroenterology Research and Practice

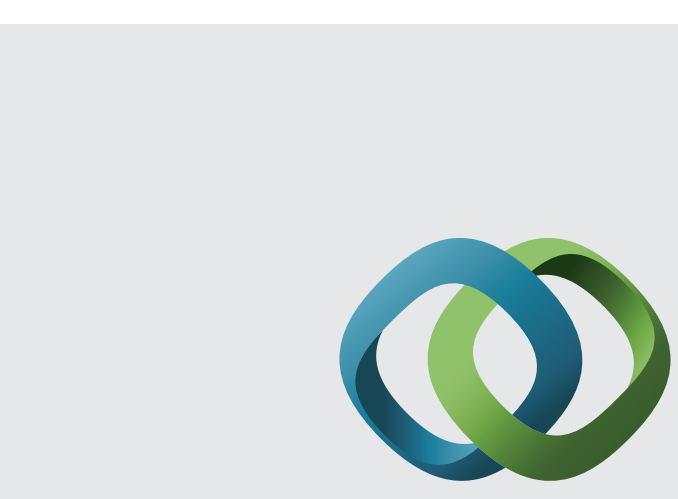

\section{Hindawi}

Submit your manuscripts at

http://www.hindawi.com
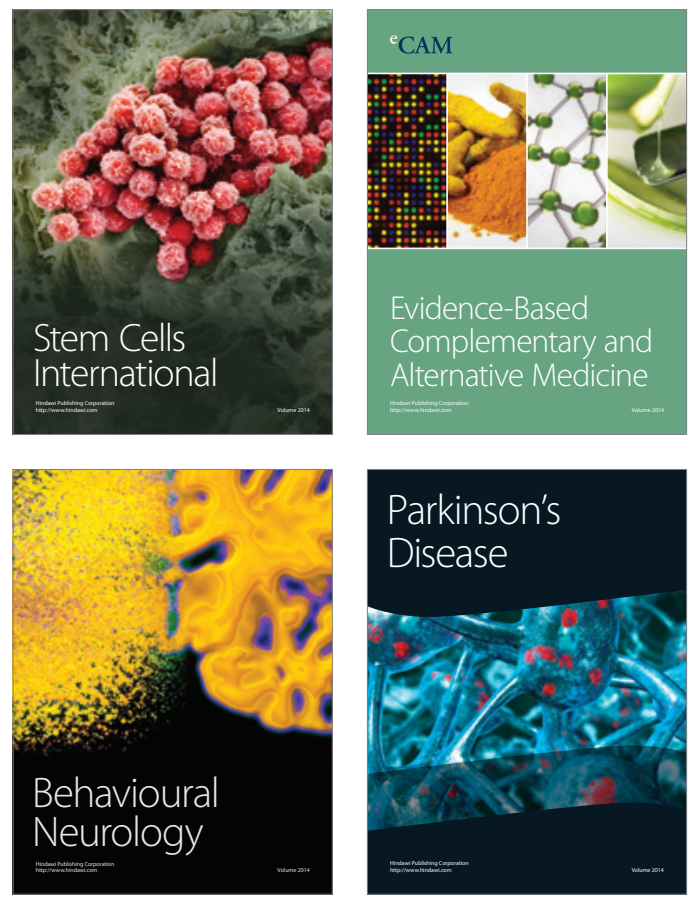
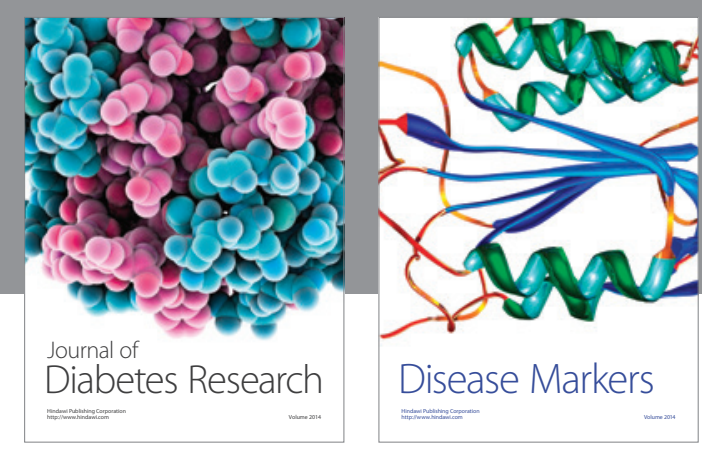

Disease Markers
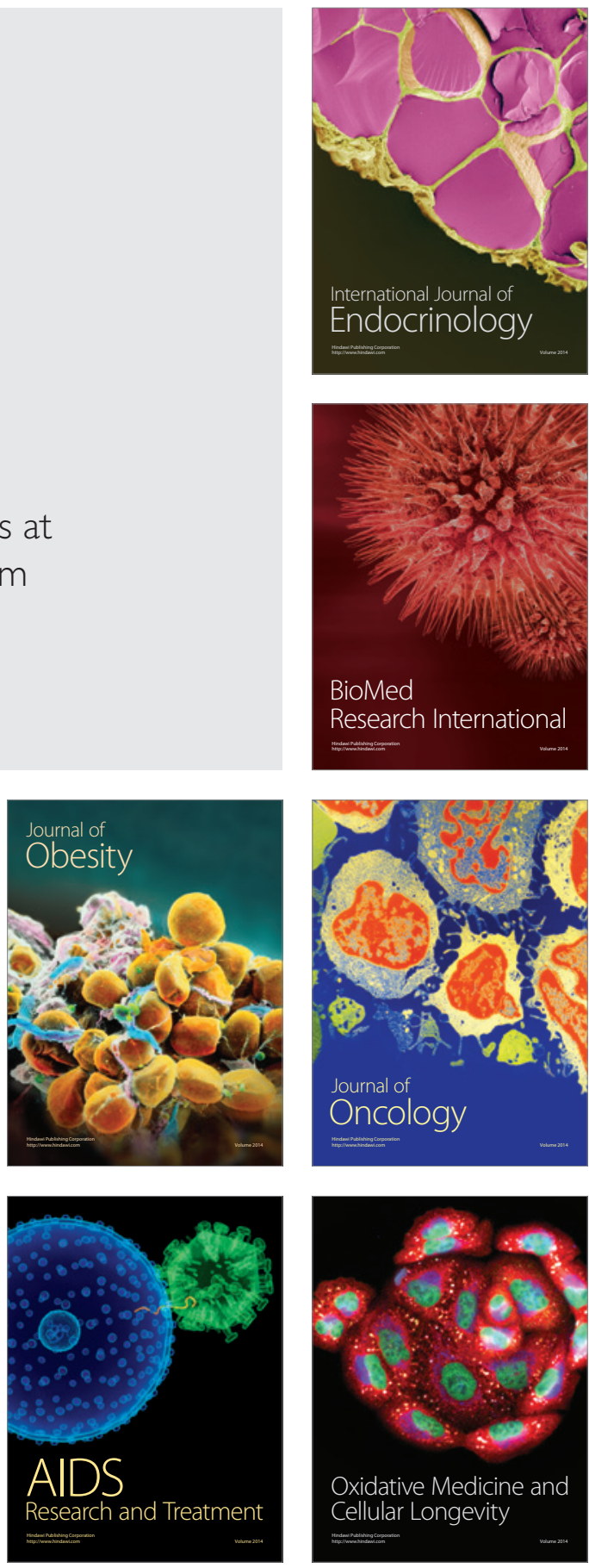